\title{
PENGGUNAAN MULTIMEDIA INTERAKTIF BERBASIS COMPUTER ASSISTED INSTRUCTION (CAI) PADA TOPIK PEMBAHASAN BAJA SEBAGAI BAHAN BANGUNAN
}

\author{
Muchlis Abdi', Gina Bachtiar ${ }^{2}$, Daryati \\ ${ }^{1}$ Alumni PTB, FT UNJ, Jakarta, Indonesia. muchlisada@yahoo.com \\ ${ }^{2}$ Dosen PTB, FT UNJ, Jakarta, Indonesia. ginbach@unj.ac.id \\ ${ }^{3}$ Dosen PTB, FT UNJ, Jakarta, Indonesia. daryati sr@unj.ac.id
}

\begin{abstract}
Abstrak
Tujuan penelitian ini dirancang untuk mengetahui perbedaan hasil belajar menggunakan CAI berbasis multimedia interaktif dengan media pembelajaran berbasis Powerpoint pada pembahasan topik baja sebagai bahan bangunan di Program Studi Pendidikan Teknik Bangunan Universitas Negeri Jakarta dan membantu siswa dalam memahami pembahasan topik tentang baja sebagai bahan bangunan dalam kursus ilmu material.

Penelitian ini adalah Pre-test Penelitian Eksperimen Benar - Post-test Design. Metode yang digunakan adalah metode eksperimental. Divalidasi oleh ahli konten media instruksional dan ahli media untuk mendapatkan uji coba kelayakan. Selanjutnya, instrumen tes diujikan pada mahasiswa Program Studi Pendidikan Teknik Bangunan tahun 2014. Setelah itu dilakukan uji lapangan kepada mahasiswa Pendidikan Program Studi Teknik Bangunan angkatan 2016. Analisis data menggunakan T-test dua sisi sampel independen melalui program SPSS V17.

Hasil penelitian ini berarti bahwa kelas eksperimen memperoleh selisih rata-rata hasil belajar (pre-test dan post-test) sebesar 33,18 dan mengalami peningkatan sebesar 16,59\%. Sedangkan kelas kontrol memperoleh selisih rata-rata hasil belajar (pre-test dan post-test) sebesar 23,64 dan mengalami peningkatan sebesar $11,82 \%$. Selanjutnya, uji-T dua sisi sampel independen dilakukan dengan memperoleh hasil uji 0,027<0,05. Jadi dapat disimpulkan perbedaan hasil belajar penggunaan multimedia interaktif berbasis CAI lebih besar dari penggunaan media pembelajaran berbasis Powerpoint pada selisih rata-rata hasil belajar siswa pada pembahasan topik baja sebagai bahan bangunan pada siswa Pendidikan Program Studi Teknik Bangunan Universitas Negeri Jakarta.
\end{abstract}

Kata kunci: Kegunaan, Multimedia Interaktif berbasis CAI, Baja sebagai bahan bangunan

\section{USE OF INTERACTIVE MULTIMEDIA BASED ON ASSOCIATED INSTRUCTIONS (CAI) ON TOPIC DISCUSSION OF STEEL AS BUILDING MATERIALS}

\author{
Muchlis Abdi', Gina Bachtiar ${ }^{2}$, Daryati ${ }^{3}$ \\ ${ }^{1}$ Alumni of PTB, FT UNJ, Jakarta, Indonesia.mucblisada@yahoo.com \\ ${ }^{2}$ Lecturer of PTB, FT UNJ, Jakarta, Indonesia.ginbach@,unj.ac.id \\ ${ }^{3}$ Lecturer of PTB, FT UNJ, Jakarta, Indonesia. daryatisn@unj.ac.id
}

\section{Abstract}

The objectives of this research was designed to determined the difference in learning outcomes using interactive multimedia based CAI with Powerpoint-based learning media on the topic discussion of steel as a building material in Education of Building Engineering Studies Program State University of Jakarta and assist students in understanding the topic discussion of steel as a building material in materials science courses. 
This research is a True Experiment Research Pre-test - Post-test Design. The method used is an experimental method. Validated by expert instructional media content and media experts to get the feasibility trial. Furthermore, the test instrument was tested on the student Education of Building Engineering Studies Program class of 2014. After that conducted field test to student Education of Building Engineering Studies Program class of 2016. Data analysis is used T-test two independent sample side through program SPSS V17.

The results of this research means that the experimental class obtain the mean difference in learning outcomes (pre-test and post-test) of 33,18 and have an increase of 16,59\%. While the control class obtain a mean difference of learning outcomes (pre-test and post-test) of 23,64 and have an increase of 11,82\%. Furthermore, T-test two independent sample side was conducted by obtain the test result of 0,027 <0,05. So it can be concluded differences in learning outcomes use of interactive multimedia based CAI is greater than the use of Powerpoint-based learning media on the difference in the average results of student learning on the topic discussion of steel as a building material on the student Education of Building Engineering Studies Program State University of Jakarta.

Keywords: Use, Interactive Multimedia Based CAI, Steel as a building material

\section{Pendahuluan}

Permasalahan dalam belajar ilmu bahan bangunan ialah hendaknya konsep dan prinsip fakta tidak diterima secara prosedural tanpa pemahaman dan penalaran. Pengetahuan tidak dapat dipindahkan begitu saja dari otak pendidik ke kepala orang lain dalam hal ini mahasiswa. Pendidik dituntut untuk memilih dan menerapkan media pembalajaran yang tepat untuk menciptakan penyampaian pengetahuan yang lebih menarik dan mampu meningkatkan hasil belajar mahasiswa. Pendidik menggunakan media papan tulis dan power point dengan metode ceramah dalam pelaksanakan kegiatan pembelajaran Ilmu Bahan Bangunan pada topik pembahasan baja sebagai bahan bangunan. Pendidik melakukan kegiatan pembelajaran dengan waktu yang singkat dengan materi yang padat, sehingga topik pembahasan tersebut harus dapat disampaikan kepada mahasiswa secara detail dan menyeluruh. Hal tersebut terkadang mahasiswa masih kurang memahami dan menalar topik pembahasan tersebut.

Dalam proses pembelajaran, pendidik sangat berperan penting sebagai pemberi pesan. Seorang pendidik seyogyanya memiliki pengetahuan tentang bagaimana berinovasi dalam pembelajaran agar kegiatan belajar mengajar lebih baik dan menarik, sehingga mahasiswa lebih termotivasi untuk memperdalam ilmu dan pengetahuan yang memberikan dampak positif pada hasil belajarnya. Di samping itu, teknologi memberikan kontribusi dalam media pembelajaran, baik di tingkat sekolah maupun perguruan tinggi dalam kehidupan sehari-hari. Pendidik dapat memanfaatkan media pembelajaran dalam proses pembelajaran seperti power point, byperlink, video tutorial, compact disk (CD) dan multimedia interaktif berbasis CAI.

$$
\text { Aspek penggunaan media }
$$
pembelajaran pada multimedia dalam kegiatan pembelajaran dapat memberikan rangsangan atau stimulus dalam belajar. Salah satu alternatif media pembelajaran adalah multimedia interaktif berbasis CAI. Adapun keunggulan multimedia interaktif berbasis CAI sebagai media pembelajaran antara lain : (1) mampu menghasilkan presentasi, game, film CD interaktif, maupun $C D$ pembelajaran, dan membuat situs web yang interaktif, menarik, dan dinamis; (2) mempunyai kemampuan interaktif dengan action script, (3) mampu membuat animasi, baik animasi interaktif maupun non-interaktif; (4) mampu 
menampilkan nilai/skor dalam kegiatan evaluasi, sehingga hal tersebut dapat memfasilitasi mahasiswa untuk belajar secara mandiri di luar jam efektif belajar di perkuliahan.

Perubahan suasana dalam proses kegiatan pembelajaran seperti multimedia interaktif berbasis CAI perlu dilakukan, seperti pengadaan animasi gambar atau gerak yang mampu menarik dan mengarah mahasiswa untuk lebih antusias pada mata kuliah ilmu bahan bangunan, hal ini dapat dijadikan sebagai alternatif untuk membuat mahasiswa lebih tertarik untuk memahami mata kuliah tersebut. Terkait dengan media pembelajaran yang digunakan, pendidik menyampaikan topik pembahasan yang diberikan kepada mahasiswa, salah satu mata kuliah wajib di program studi Pendidikan Teknik Bangunan Universitas Negeri Jakarta ialah Ilmu bahan bangunan. Ilmu Bahan Bangunan memiliki bobot 2 SKS, 2 SKS tersebut berisi tentang teori. Pada mata kuliah ini, topik pembahasan yang dibahas untuk 1 semester adalah 12 topik pembahasan, tetapi dalam penelitian ini hanya mengambil 1 topik pembahasan mengenai baja sebagai bahan bangunan. Berdasarkan uraian di atas, perlu melakukan penelitian yang berjudul "Penggunaan Mulimedia Interaktif Berbasis Computer Assisted Instruction (CAI) Pada Topik Pembahasan Baja Sebagai Bahan Bangunan”.

\section{Metode Penelitian}

Penelitian ini termasuk True Experiment Research Pre-test - Post-test Design. Metode yang digunakan dalam penelitian ini adalah metode eksperimen. Pada metode ini, pengajar memberikan perlakuan pembelajaran secara langsung kepada sampel penelitian yaitu dengan memberikan pembelajaran menggunakan multimedia interaktif pada kelas eksperimen dan pembelajaran tanpa menggunakan media power point (konvensional) pada kelas kontrol.

Tempat dan Waktu Penelitian
Penelitian dan desain multimedia interaktif berbasi CAI ini ditunjukkan untuk mahasiswa Program Studi Pendidikan Teknik Bangunan Universitas Negeri Jakarta pada mata kuliah ilmu bahan bangunan. Waktu penelitian dan desain multimedia interaktif berlangsung pada bulan April - Juni 2017.

\section{Teknik Pengambilan Sample}

Teknik pengambilan sampel dilakukan dengan cara simple random sampling atau sampel acak sederhana.

\section{Populasi}

Populasi Populasi yang terdapat dalam penelitian ini adalah homogen atau diambil dari kelas yang memiliki mahasiswa dengan tingkatan yang sama, yaitu mahasiswa angkatan 2016 yang sudah terdaftar dalam kartu rencana studi untuk mengambil mata kuliah ilmu bahan bangunan pada semester genap tahun akademik 2016/2017.

Sample

Sampel dalam penelitian ini merupakan 44 mahasiswa dengan 22 mahasiswa dari kelas A dan 22 mahasiswa dari kelas B.

\section{Teknik Pengumpulan Data}

Pengumpulan data melalui responden yang dimintai pendapat dan komentarnya tentang media pembelajaran multimedia interaktif yang dikembangkan dalam bentuk angket. Untuk Mendapatkan umpan balik komentar yang tepatdan sesuai, maka dipilih koresponden sesuai tabel berikut ini:

Tabel 1. Responden Validasi

\begin{tabular}{|l|l|l|}
\hline No & Responden & Keterangan \\
\hline 1 & $\begin{array}{l}\text { Ahli Materi Ilmu } \\
\text { Bahan Bangunan }\end{array}$ & $\begin{array}{l}\text { Dosen Teknik Sipil } \\
\text { UNJ }\end{array}$ \\
\hline 2 & Ahli Media & $\begin{array}{l}\text { Dosen Ahli Media } \\
\text { UNJ }\end{array}$ \\
\hline
\end{tabular}




\begin{tabular}{|l|l|l|}
\hline 3 & $\begin{array}{l}\text { Mahasiswa Prodi } \\
\text { Pendidikan } \\
\text { Teknik Bangunan }\end{array}$ & $\begin{array}{l}\text { Mahasiswa Angkatan } \\
\text { 2014 yang telah } \\
\text { menyelesaikan mata } \\
\text { kulian Ilmu Bahan } \\
\text { Bangunan }\end{array}$ \\
\hline 4 & $\begin{array}{l}\text { Mahasiswa Prodi } \\
\text { Pendidikan } \\
\text { Teknik Bangunan }\end{array}$ & $\begin{array}{l}\text { Mahasiswa angkatan } \\
\text { 2016 yang sudah } \\
\text { terdaftar pada mata } \\
\text { kuliah Ilmu Bahan } \\
\text { Bangunan semester } \\
\text { genap tahun akademik } \\
\text { 2016/2017 }\end{array}$ \\
\hline
\end{tabular}

Teknik Analisis Data

Data yang diperoleh berdasarkan instrumen tes akan diolah dengan cara statistik deskriptif. Statistik deskriptif adalah statistik yang digunakan untuk menganalisis data dengan cara mendeskripsikan atau menggambarkan data yang telah terkumpul sebagaimana adanya tanpa bermaksud membuat kesimpulan yang belaku umum atau generalisasi.

Instrumen tes Pre-Test dan Post-Test ini dibuat untuk mengukur hasil belajar mahasiswa pada masing-masing kelas sampel. Instrumen tes berupa soal pilihan ganda berjumlah 10 soal.

\section{Validitas}

Dalam penelitian ini uji validitas dilakukan dengan menggunakan rpbis (korelasi point biserial). Teknik korelasi point biserial menurut Arikunto (2015) mempunyai pola rumus sebagai berikut:

$$
\Gamma_{\text {inisis }}=\frac{M_{p}-M_{r}}{s_{x}} \sqrt{\frac{p}{q}}
$$

Keterangan:

$\mathrm{r}_{\text {pbis }}=$ Koefisien korelasi biserial

$\mathrm{M}_{\mathrm{p}} \quad=$ Rerata skor dari subjek yang menjawab benar bagi item yang dicari validitas

$\mathrm{M}_{\mathrm{t}} \quad=$ Rerata skor total

$\mathrm{S}_{\mathrm{t}}=$ Standar deviasi dari skor total proporsi

$\mathrm{p}=$ Proporsi mahasiswa yang menjawab benar $\left(p=\frac{\text { banyaknyapeserta didik yang benar }}{j \text { jumlah seluruh peserta didik }}\right)$

$\mathrm{q}=$ Proporsi mahasiswa yang menjawab salah $(q=1-p)$

Menurut Arikunto (2015) besarnya koefisien korelasi adalah sebagai berikut :

a. Antara 0,800 sampai dengan 1,00 : Sangat tinggi

b. Antara 0,600 sampai dengan 0,800 : Tinggi

c. Antara 0,400 sampai dengan 0,600 : Cukup

d. Antara 0,200 sampai dengan 0,400 : Rendah

e. Antara 0,00 sampai dengan 0,200 : Sangat rendah

\section{Reliabilitas}

Untuk menghitung reliabilitas instrumen digunakan rumus K-R. 20 sebagai berikut:

$$
r_{11}=\left(\frac{n}{n-1}\right)\left(\frac{s^{2}-\sum p q}{s^{2}}\right)
$$

\section{Keterangan:}

$\mathrm{r}_{11}=$ reliabilitas tes secara keseluruhan

$\mathrm{p}=$ proporsi subjek yang menjawab item dengan benar

$\mathrm{q}=$ proporsi subjek yang menjawab item dengan salah $(\mathrm{q}=1-\mathrm{p})$

$\sum \mathrm{pq}=$ jumlah hasil perkalian antara $\mathrm{p}$ dan $\mathrm{q}$

$\mathrm{n} \quad=$ banyaknya item

$\mathrm{S}=$ standar deviasi dari tes (standar deviasi adalah akar varians)

\section{Analisis Persyaratan}

Sebelum melakukan teknik analisis statistik yang akan digunakan, terlebih dahulu memeriksa keabsahan sampel yaitu dengan menggunakan uji normalitas dan uji homogenitas. 


\section{A. Uji Normalitas}

Uji normalitas dalam penelitian ini menggunakan uji Liliefors (Lo). adapun menurut Sudjana (2005) langkah-langkah pengujian normalitas adalah :

a. Data pengamatan $\mathrm{x}_{1}, \mathrm{x}_{2}, \mathrm{x}_{3}, \ldots \ldots, \mathrm{x}_{\mathrm{n}}$ dijadikan bilangan baku $z_{1}, Z_{2}, Z_{3}, \ldots \ldots . ., Z_{n}$ dengan menggunakan rumus (dengan $\bar{x}$ dan $\mathrm{s}$ masing-masing merupakan rerata dan simpangan baku)

b. Untuk setiap bilangan baku ini dengan menggunakan daftar distribusi normal baku, kemudian dihitung peluang $F_{\left(Z_{i}\right)}$ $=\mathrm{P}\left(\mathrm{z} \leq \mathrm{z}_{\mathrm{i}}\right)$.

c. Selanjutnya dihitung proporsi $z_{1}, z_{2}, z_{3}, \ldots$, $z_{n}$ yang lebih kecil atau sama dengan $z_{i}$. jika proporsi ini dinyatakan oleh $S^{\left(z_{i}\right)}$ maka :

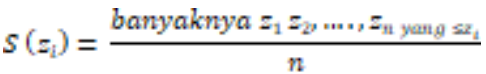

d. Hitung selisish $\left|F\left(z_{i}\right)-S\left(z_{i}\right)\right|$, kemudian tentukan harga mutlaknya.

e. Ambil harga yang paling besar di antara harga-harga mutlak selisih tersebut, harga tersebut adalah $\mathrm{L}_{\text {hitung. }}$. berikut :

Hipotesis yang diajukan sebagai

$\mathrm{H}_{\mathrm{o}}$ : Sampel berasal dari populasi yang berdistribusi normal

$\mathrm{H}_{1}$ : Sampel tidak berasal dari populasi yang berdistribusi normal berikut :

Dengan kriteria pengujian sebagai

Jika $\mathrm{L}_{\text {hitung }} \leq \mathrm{L}_{\text {tabel }}, \mathrm{H}_{0}$ diterima.

Jika $\mathrm{L}_{\text {hitung }} \geq \mathrm{L}_{\text {tabel }}, \mathrm{H}_{0}$ ditolak.

Dimana $\mathrm{L}_{\text {tabel }}$ dapat diperoleh melalui $\mathrm{df}($ degree of freedom $)=\mathrm{n}($ taraf signifikan $5 \%)$, $\mathrm{n}=$ jumlah sampel)

\section{B. Uji Homogenitas}

Pada penelitian ini digunakan uji Bartlett untuk menguji homogenitas varians dari dua kelas data. Adapun Supardi (2013:145) menjelaskan langkah-langkah uji Bartlett :

a. sajikan data semua kelas sampel

b. menghitung rerata (mean) dan varian serta derajat kebebasan (dk) setiap kelas data yang akan diuji homogenitasnya. c. Sajikan $\mathrm{dk}$ dan varian $\left(S^{2}\right)$ tiap kelas sampel dalam tabel, serta sekaligus hitung nilai logaritma dari setiap varian kelas dan hasil kali dk dengan logaritma varian dari tiap kelas sampel.

d. Hitung varian gabungan dari semua kelas sampel :

$$
s^{2}=\frac{\sum\left(m_{1}-1\right) s_{i}^{2}}{\sum\left(n_{1}-1\right)}
$$

e. Hitung harga logaritma varian gabungan dan harga satuan Bartlett (B) dengan rumus :

$$
B=\left(\log e^{2}\right) \sum\left(n_{1}-1\right)=\left(\log s^{2}\right) \sum_{d k}
$$

f. Hitung nilai chi kuadrat $\left(X_{\text {hitung }}^{2}\right)$ dengan rumus :

$$
X_{\text {mining }}^{2}=(\ln 10)\left(B-\sum d k \cdot \log s_{i}^{2}\right)
$$

g. Tentukan harga chi kuadrat table $\left(X_{\text {tabel }}^{2}\right)$, pada taraf nyata misal $\alpha=$ 0,05 dan derajat kebebasan $(\mathrm{dk})=\mathrm{k}-$ 1, yaitu :

$$
X_{\text {tabel }}^{2}=X_{(1-a)(k-1)}
$$

(dalam hal ini $\mathrm{k}=$ banyaknya kelas sampel)

h. Menguji hipotesis homogenitas data dengan cara membandingkan nilai $\left(X_{\text {hitung }}^{2}\right)_{\text {dengan }}\left(X_{\text {tabel }}^{2}\right)$.

Hipotesis yang diuji adalah :

$\mathrm{H}_{0} \quad: \quad \sigma_{1}^{2}=\sigma_{2}^{2}=\ldots=\sigma_{n}^{2} \quad$ (semua populasi mempunyai varian yang homogen)

$\mathrm{H}_{1}$ : Bukan $\mathrm{H}_{0}$ (ada populasi mempunyai varian yang tidak homogen)

Kriteria pengujian adalah :

Tolak $\mathrm{H}_{0}$ jika $X_{\text {hitung }}^{2} X_{(1-a)(k-1)}^{2}$ atau $X_{\text {hitung }}^{2} X_{\text {tabel }}^{2}$

Terima $\mathrm{H}_{0}$ jika $X_{\text {hitung }}^{2} \leq X_{(1-a)(k-1)}^{2}$ atau $X_{\text {hitung }}^{2} \leq X_{\text {tabel }}^{2}$

\section{Analisis Data}

Jika sampel berdistribusi normal dan homogen, maka dilakukan uji parametrik dengan menguji hipotesis statistik menggunakan rumus uji-t dengan taraf 
signifikansi 5\%. Berikut ini rumus uji t yang digunakan :

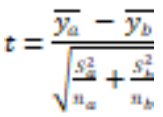

Keterangan :

$\overline{y_{a}}=$ Nilai rerata sampel kelas eksperimen

$\overline{y_{a}}=$ Nilai rerata sampel kelas kontrol

$S_{a}^{2}=$ Varians kelas eksperimen

$S_{b}^{2}=$ Varians kelas kontrol

Apabila $t_{\text {hitung }} \leq t_{\text {tabel }}$ maka $\mathrm{H}_{0}$ diterima

sedangkan apabila $t_{\text {hitung }}>t_{\text {tabel }}$ maka $\mathrm{H}_{0}$ ditolak.

\section{Hasil Penelitian dan Pembahasan}

Penelitian dilaksanakan pada bulan April - Juni 2017. Pelaksanaan penelitian terdiri dari 3 proses yaitu pre-test, perlakuan, dan post-test. Pre-test adalah pengambilan nilai kemampuan awal dari mahasiswa Program Studi Pendidikan Teknik Bangunan Universitas Negeri Jakarta. Perlakuan (treatment) adalah proses pembelajaran materi baja sebagai bahan bangunan dengan menggunakan multimedia interaktif berbasis CAI pada kelas eksperimen dan media pembelajaran berbasis Powepoint pada kelas kontrol. Post-test adalah pengambilan nilai kemampuan akhir kedua kelompok setelah adanya perlakuan.

\section{Uji Kelayakan Media Pembelajaran Oleh Abli Media}

Uji kelayakan ahli media oleh Dosen Teknologi Pendidikan Pasca Sarjana Universitas Negeri Jakarta, yakni Dr. Moch. Sukardjo, M.Pd. Pada uji kelayakan oleh ahli media, aspek penilaian pada media meliputi: (1) Kemudahan Navigasi, (2) Kandungan Kognisi, (3) Presentasi Informasi Penilaian, (4) Integrasi Media, (5) Artistik dan Estetika, dan (6) Fungsi Keseluruhan.

Berdasarkan penelitian yang dilakukan, penilaian total dari ahli media mengenai media pembelajaran adalah $90,09 \%$. Sesuai dengan persentase penilaian mengenai pengelompokkan kategori kualitas berdasarkan persentase, maka hasil tersebut termasuk kategori sangat sesuai untuk digunakan dan dapat diteruskan ketahap pengujian selanjutnya.

\section{Uji Kelayakan Oleh Abli Media}

Uji kelayakan ahli media oleh Dosen Teknologi Pendidikan Pasca Sarjana Universitas Negeri Jakarta, yakni Dr. Moch. Sukardjo, M.Pd. Pada uji kelayakan oleh ahli media, aspek penilaian pada media meliputi: (1) Kemudahan Navigasi, (2) Kandungan Kognisi, (3) Presentasi Informasi Penilaian, (4) Integrasi Media, (5) Artistik dan Estetika, dan (6) Fungsi Keseluruhan.

Setelah dilakukan penelitian, penilaian total dari ahli media mengenai media pembelajaran adalah 90,09\%. Sesuai dengan persentase penilaian mengenai pengelompokkan kategori kualitas berdasarkan persentase, maka hasil tersebut termasuk kategori sangat sesuai untuk digunakan dan dapat diteruskan ketahap pengujian selanjutnya.

\section{Hasil Kelayakan Oleh Abli Materi}

Uji kelayakan ahli materi oleh Dosen Pengampu Mata Kuliah Ilmu Bahan Bangunan Program Studi Pendidikan Teknik Bangunan Universitas Negeri Jakarta, yakni Drs. Prihantono, S.T, M.Eng. Pada uji kelayakan oleh ahli materi, aspek penilaian pada media meliputi: Kesesuaian Isi dan Tujuan, (2) Desain Interface, (3) Desain Instruksional, dan (4) Konten.

Penilaian total dari ahli materi 1 mengenai media pembelajaran adalah $87,29 \%$. Sesuai dengan persentase penilaian mengenai pengelompokkan kategori kualitas berdasarkan persentase, maka hasil tersebut termasuk kategori sangat sesuai untuk digunakan dan dapat diteruskan ketahap pengujian selanjutnya.

Penilaian total dari ahli materi mengenai media pembelajaran adalah $73,19 \%$. Sesuai dengan persentase penilaian mengenai pengelompokkan kategori kualitas berdasarkan persentase, maka hasil tersebut termasuk kategori sesuai untuk 
digunakan dan dapat diteruskan ketahap pengujian selanjutnya.

\section{Hasil Evaluasi Media Terbadap Abli}

Pengujian media dan materi diberikan kepada 3 orang ahli diantaranya 2 orang ahli materi yaitu Bapak Drs. Prihantono, S.T, M.Eng (Dosen Pengampu Ilmu Bahan Bangunan Program Studi Pendidikan Teknik Bangunan UNJ) dan Ibu Anisah, S.T, M.T (Dosen Program Studi Pendidikan Teknik Bangunan UNJ) serta 1 orang ahli media yaitu Bapak Dr. Moch. Sukardjo, M.Pd (Dosen Teknologi Pendidikan Pasca Sarjana UNJ).

Skor maksimum didapatkan berdasarkan lembar validasi, yaitu jumlah pernyataan $\times$ jumlah skor tertinggi. Berikut data perhitungannya:

1. Ahli Materi I (Dosen Pengampu Mata Kuliah Ilmu Bahan Bangunan Program Studi Pendidikan Teknik Bangunan UNJ) : $29 \times 5=145$

2. Ahli Materi II (Dosen Program Studi Pendidikan Teknik Bangunan UNJ) : 29 $\times 5=145$

3. Ahli Media (Dosen Teknologi Pendidikan Pasca Sarjana UNJ) : $36 \times 5$ $=180$

\section{Pembahasan Hasil Penelitian}

Tujuan penelitian ini adalah untuk mengetahui perbandingan penggunaan multimedia interaktif berbasis CAI dengan media pembelajaran berbasis Powerpoint dalam meningkatkan hasil belajar siswa pada pada topik pembahasan baja sebagai bahan bangunan. Subjek penelitian ini berjumlah 44 siswa yang dibagi menjadi dua kelompok yaitu kelompok kelas eskperimen (22 mahaiswa) dan kelompok kelas kontrol (22 mahasiswa). Sebelum melakukan uji coba lapangan terlebih dulu peneliti melakukan evaluasi terhadap beberapa ahli untuk mengetahui kelayakan media yang akan diujicobakan.

Pada tahap evaluasi dilakukan penilaian media yang dibuat untuk beberapa ahli diantaranya 2 ahli materi serta 1 ahli media. Penilaian dari ahli tersebut bertujuan untuk mengetahui kelayakan media yang telah dibuat, penilaian oleh para ahli diperoleh sebagai berikut : (1) Validasi oleh ahli materi 1 menyatakan sangat sesuai dengan persentase $87,29 \%$. (2) Validasi oleh ahli materi II menyatakan sesuai dengan persentase $73,19 \%$. (3) Validasi oleh ahli media menyatakan sangat sesuai dengan persentase $90,09 \%$. Sehingga dapat disimpulkan bahwa multimedia interaktif berbasis CAI ilmu bahan bangunan dari segi materi dan media layak dan sangat sesuai untuk digunakan dalam proses pembelajaran.

Disamping itu, dilakukan uji coba instrumen tes untuk menguji instrumen tes yang dilakukan dengan mengambil sampel sebanyak 16 mahasiswa Program Studi Pendidikan Teknik Bangunan yang telah menyelesaikan studi mata kuliah Ilmu Bahan Bangunan melalui tes pilihan ganda sebanyak 10 soal. Kompetensi dasar yang diuji pada uji coba tes adalah Baja sebagai bahan bangunan. Berdasarkan hasil uji coba instrumen soal didapatkan 7 soal valid dan 3 soal belum valid sehingga perlu dilakukan perbaikan redaksi soal. 7 butir soal tersebut dilakukan pengujian reliabilitas dengan menghasilkan nilai KR sebesar 0,696 yang dikategorikan tinggi.

Setelah dilakukan uji instrumen tes, selanjutnya dilakukan penelitian penggunaan multimedia interaktif berbasis CAI. Adapun tempat penelitian adalah Program Studi Pendidikan Teknik Bangunan Universitas Negeri Jakarta. uji coba dilakukan pada mahasiswa angkatan 2016 yang sedang menempuh mata kuliah Ilmu Bahan Bangunan (IBB) pada semester genap tahun akademik 2016/2017. Pada penelitian ini, sampel dibagi menjadi dua kelas, yaitu : kelas eksperimen dan kelas kontrol. Pada kelas eksperimen, mahasiswa menggunakan media berupa multimedia interaktif berbasis CAI tanpa suatu tindakan mengajar di kelas. Sedangkan pada kelas kontrol, mahasiswa menggunakan media power point dengan metode ceramah.

Pada kelas eksperimen, mahasiswa memberikan respon positif berupa 
partisipasi aktif untuk belajar dan memiliki daya tarik pada penampilannya. Di samping itu, multimedia interaktif ini memberikan kemudahan bagi mahasiswa dalam memahami materi pada standar kompetensi baja sebagai bahan bangunan karena penyampaian materi dikemasi secara jelas dan menarik serta didukung dengan animasi dan video pembelajaran. Sedangkan pada kelas kontrol, mahasiswa memberikan respon yang cenderung kurang memperhatikan penjelasan pada media.

Dalam uji coba lapangan ini mengambil data berupa tes. Tes digunakan untuk meneliti keefektifan multimedia interaktif terhadap hasil belajar mahasiswa baik di kelas eksperimen maupun kelas kontrol.. Setelah dilakukan uji coba, selanjutnya dilakukan pengukuran pada hasil belajar mahasiswa melalui tes pilihan ganda sebanyak 10 soal. Kompetensi dasar yang diuji pada tes adalah baja sebagai bahan bangunan. Berdasarkan nilai hasil belajar yang diperoleh, kelas eksperimen memperoleh selisih rerata hasil belajar (pretest \& post-test) sebesar 33,18 dan peningkatan yang terjadi sekitar 16,59\%. Sedangkan pada kelas kontrol, selisih rerata hasil belajar (pre-test \& post-test) konstruksi bangunan sebesar 23,64 dan peningkatan yang terjadi sebesar $11,82 \%$. Maka dapat disimpulkan bahwa rerata hasil belajar kelas eksperimen mengalami peningkatan lebih baik dibandingkan dengan kelas kontrol.

Hal tersebut sesuai dengan manfaat media oleh Sadiman, menurut Sadiman (2010) menyampaikan fungsi media pebelajaran secara umum, adalah sebagai berikut : (a) memperjelas penyajian pesan agar tidak terlalu bersifat verbalistis, (b) mengatasi keterbatasan ruang, waktu, dan gaya indera, misalnya objek yang terlalu besar untuk dibawa ke dalam kelas dapat diganti dengan realita, gambar, film bingkai, film, atau model (c) meningkatkan kegairahan dalam belajar, memungkinkan interaksi langsung antara anak didik dengan lingkungan, dan mengatasi sikap pasif anak didik dan, (d) memberikan rangsangan yang sama, dapat menyamakan pengalaman dan menimbulkan persepsi sama siswa terhadap isi pelajaran.

\section{Kesimpulan}

Dalam penelitian ini menunjukkan bahwa terdapat perbedaan hasil belajar pada penggunaan multimedia interaktif berbasis CAI dengan media pembelajaran berbasis Powerpoint pada topik pembahasan baja sebagai bahan bangunan memberikan yang signifikan. Hal ini dibuktikan pada proses pembelajaran di kelas. Hal tersebut didukung dengan perolehan selisih rerata hasil belajar (pre-test \& post-test) pada kelas eksperimen dengan penggunaan multimedia interaktif berbasis CAI sebesar 33,18 dan peningkatan yang terjadi sekitar 16,59\%. Sedangkan pada kelas kontrol dengan penggunaan multimedia interaktif berbasis Powerpoint, selisih rerata hasil belajar (pretest \& post-test) sebesar 23,64 dan peningkatan yang terjadi sekitar $11,82 \%$.

$\mathrm{Hal}$ tersebut mengindikasikan bahwa terdapat perbedaan hasil belajar penggunaan multimedia interaktif berbasis CAI turut berperan dalam peningkatan hasil belajar mahasiswa yang lebih besar pada kelas eksperimen dibandingkan dengan penggunaan media pembelajaran berbasis Powerpoint pada kelas kontrol. Maka dapat disimpulkan bahwa perbedaan hasil belajar penggunaan multimedia interaktif berbasis CAI lebih tinggi dibandingkan dengan penggunaan media pembelajaran berbasis Powerpoint terhadap selisih rerata hasil belajar mahasiswa pada topik pembahasan baja sebagai bahan bangunan di Program Studi Pendidikan Teknik Bangunan Universitas Negeri Jakarta.

\section{Implikasi}

Berdasarkan hasil penelitian ini maka peneliti mengajukan beberapa saran diantaranya:

1. Media ini dimanfaatkan sebagai media pembelajaran dalam proses pembelajaran pada topik pembahasan baja sebagai bahan bangunan. 
2. Perlu dilakukan penelitian lanjutan untuk penggunaan multimedia interaktif berbasis CAI dengan materi yang berbeda pada mata kuliah ilmu bahan banguna. Hal ini ditujukan agar media pembelajaran yang dihasilkan lebih berkualitas.

Saran

Berdasarkan hasil penelitian maka tindak lanjut yang dapat diberikan diantaranya :

1. Multimedia interaktif berbasis CAI yang dibuat lebih optimal jika pendidik meningkatkan inovasi yang terbaru sehingga kegiatan pembelajaran menjadi bervariasi.

2. Multimedia interaktif berbasis CAI lebih bermanfaat jika digunakan oleh peserta didik dengan dibimbing oleh pendidik pada mata kuliah yang bersangkutan, sehingga dapat mempermudah dalam memahami materi dan meningkatkan hasil belajar peserta didik.

3. Pengembangan multimedia interaktif berbasis CAI ini membutuhkan keterampilan serta waktu yang lebih, agar media yang dihasilkan sesuai dengan kebutuhan peserta didik dalam hal ini mahasiswa.

4. Pada proses pelaksanaannya multimedia intraktif berbasis CAI ini lebih optimal digunakan jika sarana komputer di perkuliahan dapat digunakan pada mata kuliah ilmu bahan bangunan, agar peserta didik dapat mengakses media secara individu.

\section{Daftar Pustaka}

Arikunto, S. 2015. Dasar-Dasar Evaluasi Pendidikan. Jakarta : Bumi Aksara.

Sadiman, A. S,dkk. 2010. Media Pendidikan : Pengertian, Pengembangan dan Pemanfaatannya. Jakarta : Rajawali Pers.
Sudjana . 2005 . Metode Statistika Edisi ke-6. Bandung: Tarsito 